\title{
Learning New Letter-like Writing Patterns Explicitly and Implicitly in Children and Adults
}

\section{Jongbloed-Pereboom, A. Overvelde, M. W. G. Nijhuis-van der Sanden \& B. Steenbergen}

To cite this article: M. Jongbloed-Pereboom, A. Overvelde, M. W. G. Nijhuis-van der Sanden \& B. Steenbergen (2018) Learning New Letter-like Writing Patterns Explicitly and Implicitly in Children and Adults, Journal of Motor Behavior, 50:6, 677-688, DOI: 10.1080/00222895.2017.1407287

To link to this article: https://doi.org/10.1080/00222895.2017.1407287

曲 Published online: 15 Dec 2017.

Submit your article to this journal $\asymp$

Џll Article views: 107

View Crossmark data \lceil 


\title{
Learning New Letter-like Writing Patterns Explicitly and Implicitly in Children and Adults
}

\author{
M. Jongbloed-Pereboom ${ }^{1 \star}$, A. Overvelde ${ }^{2}$, M. W. G. Nijhuis-van der Sanden ${ }^{2}{ }^{2}$, B. Steenbergen ${ }^{1,3}$ \\ ${ }^{1}$ Radboud University, Behavioural Science Institute, Nijmegen, The Netherlands. ${ }^{2}$ Radboud University Medical Center, \\ Radboud Institute for Health Sciences, Scientific Institute for Quality of Healthcare, Nijmegen, The Netherlands. ${ }^{3}$ Australian \\ Catholic University, School of Psychology, Melbourne, Australia.
}

\begin{abstract}
A handwriting task was used to test the assumption that explicit learning is dependent on age and working memory, while implicit learning is not. The effect of age was examined by testing both, typically developing children (5-12 years old, $n=81)$ and adults $(n=27)$ in a counterbalanced within-subjects design. Participants were asked to repeatedly write letter-like patterns on a digitizer with a non-inking pen. Reproduction of the pattern was better after explicit learning compared to implicit learning. Age had positive effects on both explicit and implicit learning; working memory did not affect learning in either conditions. These results show that it may be more effective to learn writing new letter-like patterns explicitly and that an explicit teaching method is preferred in mainstream primary education.
\end{abstract}

Keywords: Handwriting, Children, Implicit, Explicit, Working Memory

\section{Introduction}

W hen children start learning to write, they do so by reproducing letters and words. There have been few studies on how to learn handwriting patterns (Berninger et al., 1997; Naka, 1998; Vinter \& Chartrel, 2010), and in primary schools teachers combine methods, such as imitation, tracing, and verbal instruction (Graham et al., 2008). How these methods affect the learning process is not clear, nor is it clear how the learning process is influenced by individual factors. In this study, we compared an explicit and implicit learning method, and assessed if explicit and implicit learning of new letter-like patterns differed for different age groups and working memory capacities. We adopted the definitions of Kleynen et al. (2014) who defined explicit learning as: "learning which generates verbal knowledge of movement performance (e.g., facts and rules), involves cognitive stages within the learning process and is dependent on working memory involvement.", and implicit learning as: "learning which progresses with no or minimal increase in verbal knowledge of movement performance (e.g., facts and rules) and without awareness. Implicitly learned skills are (unconsciously) retrieved from implicit memory.". We assumed that explicit learning would be positively influenced by age and working memory, and implicit learning was expected to be independent of age and working memory (e.g., Kleynen et al., 2014; Maxwell, Masters, \& Eves, 2003; Meulemans, van der Linden, \& Perruchet, 1998). The results will inform the effectiveness of teaching methods and may lead to recommendations for interventions in children and adults with handwriting problems.

Handwriting problems are among the most common reasons for referring school-age children to physiotherapy or occupational therapy services (Bosga-Stork et al., 2009; Hammerschmidt \& Sudsawad, 2004). The prevalence of handwriting problems in school-age children varies between 5 and 37\% (Hamstra-Bletz \& Blöte, 1993; Karlsdottir \& Stefansson, 2002; Overvelde \& Hulstijn, 2011a; Rubin \& Henderson, 1982; Smits-Engelsman, Niemeijer, \& van Galen, 2001). Moreover, most children with learning disabilities experience problems with fine motor activities and/or handwriting problems (Clements, 1966; Jongmans, Smits-Engelsman, \& Schoemaker, 2003; Rourke, Ahmad, Collins, Hayman-Abello, \& Warriner, 2002; Tamopol \& Tamopol, 1977), and handwriting difficulties are frequently observed in children with developmental coordination disorder (DCD; APA, 2013; Blank, Smits-Engelsman, Polatajko, \& Wilson, 2012). The prevalence of handwriting problems in adults is less clear, several components of handwriting have been studied, but there is no recent normative data (van Drempt, McCluskey, \& Lannin, 2011). It is known that handwriting difficulties persist into adulthood in individuals with DCD (Kirby, Edwards, \& Sugden, 2011).

Early learning of handwriting can be done via explicit and implicit learning methods. In explicit learning, individuals are aware of how to perform a task and the expected outcome of a task. Explicit learning is guided by visual and / or verbal instructions, feedback and the individual may learn from mistakes made during learning. The result is that the performer builds up rules on how to perform a task or skill and that the skill can be consciously recalled (Destrebecqz \& Cleeremans, 2001; Kleynen et al., 2014; Kleynen et al., 2015; Nissen \& Bullemer, 1987). The goal of explicit instructions is to generate declarative knowledge on how to perform (parts of) the task through a set of visual and/or verbal instructions and via feedback. For example, in teaching handwriting the teacher can use explicit cues to show how a letter is produced or the teacher may let the

*Correspondence address: M. Jongbloed-Pereboom, Radboud University Nijmegen, Behavioural Science Institute, PO Box 9104, 6500 HE Nijmegen, The Netherlands. e-mail: m.jongbloedpereboom@gmail.com

Color versions of one or more of the figures in the article can be found online at www.tandfonline.com/vjmb. 
student reflect on his/her own work (Graham et al., 2008). Using explicit methods will lead to a loading on working memory in the early phases of learning. In a later phase, when writing becomes automated, working memory is freed-up to be used for other, higher level, writing processes (Berninger et al., 1997).

Implicit learning, on the other hand, is the ability to acquire a new skill without a corresponding increase in knowledge about the skill itself (Destrebecqz \& Cleeremans, 2001; Kleynen et al., 2014; Nissen \& Bullemer, 1987). Individuals are not aware of the regularities governing the skill, and the procedural knowledge gained via implicit learning is therefore difficult or even impossible to access consciously and/or report verbally. In implicit learning of handwriting patterns, the focus of attention is on an external goal, and proprioceptive experiences are coupled to the results (Poolton \& Zachry, 2007; Wulf, Hoss, \& Prinz, 1998). Consequently, and compared to explicit learning, there is less loading on working memory. Examples of implicit learning of handwriting are tracing tasks and pursuit rotor tasks (Overvelde \& Hulstijn, 2011b; Willingham, 1998).

Several studies have shown that learning to handwrite patterns is more effective when using explicit instructions (Berninger et al., 1997; Naka, 1998; Vinter \& Chartrel, 2010). In line, explicit methods are predominantly used in task-oriented therapies to improve handwriting (Smits-Engelsman et al., 2013). In educational practice, a combination of methods is used (Graham et al., 2008) and effectiveness may be related to task factors, individual factors and environmental factors (Schmidt \& Lee, 2013).

In two previous studies, the differences between learning new letter-like patterns implicitly or explicitly were examined. Overvelde and Hulstijn (2011b) examined learning writing of unfamiliar abstract patterns with the characteristics of letters in children who were good and poor writers. Children wrote with a non-inking pen on a digitizing tablet. Different conditions were compared including an explicit verbal instructed condition and an implicit moving target condition. Results showed improved learning, i.e., more accurate reproduction of the pattern, for the explicit, verbal condition compared to the implicit method. In a second study (Jongbloed-Pereboom, Peeters, Overvelde, Nijhuis-van der Sanden, \& Steenbergen, 2015) examining children with physical and multiple disabilities (study group) and a control group of typically developing children, all children were able to learn both explicitly and implicitly, but the study group learned somewhat better in the implicit condition. In the control group, no difference in learning was observed between the explicit condition and the implicit condition.

Two factors that are known to be important for motor learning are age and working memory. Specifically, age and working memory affect the first cognitive phase of (explicit) motor learning (Fitts \& Posner, 1967; Halsband \& Lange, 2006; Meulemans et al., 1998). As the cognitive phase in implicit learning is absent, this learning method is relatively independent of age and working memory (Maxwell et al., 2003; Meulemans et al., 1998; Steenbergen, van der Kamp, Verneau, Jongbloed-Pereboom, \& Masters, 2010). Moreover, implicit learning is thought to have evolved earlier than explicit learning, and therefore more stable and resilient to cognitive factors (Reber, 1992).

The aim of the present study was to assess explicit and implicit learning of a new letter-like pattern in a counterbalanced within-subjects design in both children (5-12 years old) and adults and to examine the effects of age and working memory in learning implicitly and explicitly. To distinguish explicit and implicit motor learning in the present study, participants practiced the writing pattern under different circumstances. In the explicit condition, participants were told to learn a pattern, in the implicit condition they were not. In line with literature, we expected that explicit learning would be the more effective teaching method in typically developing children and adults. Regarding the effects of age and working memory on explicit and implicit learning of a new letter-like pattern, we hypothesized explicit learning to be affected by age and working memory, i.e., we expected positive effects of both age and working memory. Conversely, implicit learning is expected to be independent of age and working memory.

\section{Method}

\section{Participants}

Eighty-one typically developing children (39 males) aged 5-12 years were included in this study, and 27 adult students (14 males, age range 17-22). Children were recruited and tested at two primary schools, while students were recruited and tested at the University. All participants had a normal IQ ( $>84$, tested with the Wechsler non-verbal test; Wechsler \& Naglieri, 2008), were born at term, had no neurological or physical disorders, and had no behavioral problems.

\section{Procedure}

The study was approved by the Ethical Committee of the Faculty of Social Sciences (ECSW2013-1811-147). Participants or participants' parents gave informed consent and filled in a questionnaire about their own or their child's health to exclude medical or psychological conditions that could influence learning the task. Participants were asked to write letter-like patterns on a digitizer. The patterns were unfamiliar to all participants, but had the characteristics of letter patterns. Two different patterns were used during the explicit and implicit condition, which had the same trajectory length and consisted of the same elements (see Figure 1). All participants performed both the explicit and implicit condition of the learning task and the two different letter-like patterns in a counterbalanced design (leading to 

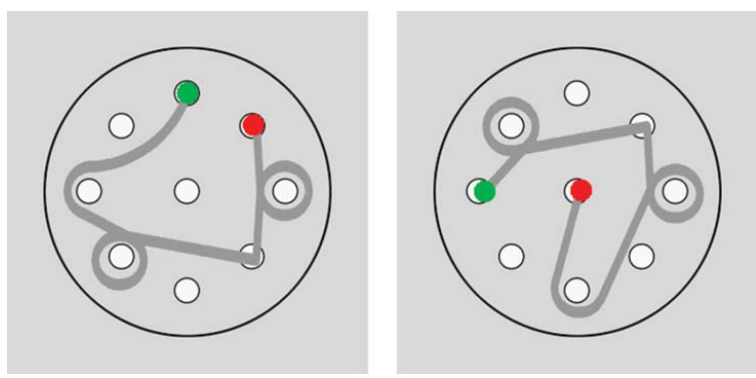

FIGURE 1. Illustration of the abstract letter-like patterns used in the writing task. In the explicit condition, the trajectory was presented. When children started writing, the trajectory disappeared until they reached the end position. In the implicit condition, the grey trace was not shown on the screen, but only the start (green dot) and end position (red dot) were marked. In the implicit condition a circular yellow target moved along the invisible pre-recorded trajectory. In the test phase, children had to reproduce the learned sequences without the help of the moving target or verbal instruction. The start and end position were still marked.
TABLE 1. Learning task: Four conditions.

\begin{tabular}{ccc}
\hline \hline & Learning task part 1 & Learning task part 2 \\
\hline Test Sequence & & \\
A & Explicit Pattern 1 & Implicit Pattern 2 \\
B & Explicit Pattern 2 & Implicit Pattern 1 \\
C & Implicit Pattern 1 & Explicit Pattern 2 \\
D & Implicit Pattern 2 & Explicit Pattern 1 \\
\hline All participants performed both the explicit and implicit condition \\
of the learning task and the two different letter-like patterns in a \\
counterbalanced design, leading to four different test sequences. \\
Each participant was assigned to one of these sequences. Two dif- \\
ferent patterns were used during the explicit and implicit condition, \\
which had the same trajectory length and consisted of the same ele- \\
ments (see also Figure 1). Both parts of the learning task consisted \\
of 25 training trials (5 $\times 5$ blocks), a short break, and a 10 trial test \\
phase (5 52 blocks) in each condition.
\end{tabular}

assessed after the learning task in the same session. IQ was tested for inclusion purposes (IQ > 84), motor proficiency was assessed to control for this factor in the analysis.

four different test sequences, see Table 1). The assessment of the learning task lasted 30-45 minutes. For children IQ, motor proficiency and visual working memory were assessed in a separate session, that lasted approximately one hour. For adult students, these background tests were

\section{Measures}

\section{Learning Task}

The handwriting task was based on a task designed by Overvelde and Hulstijn (2011b). To better compare
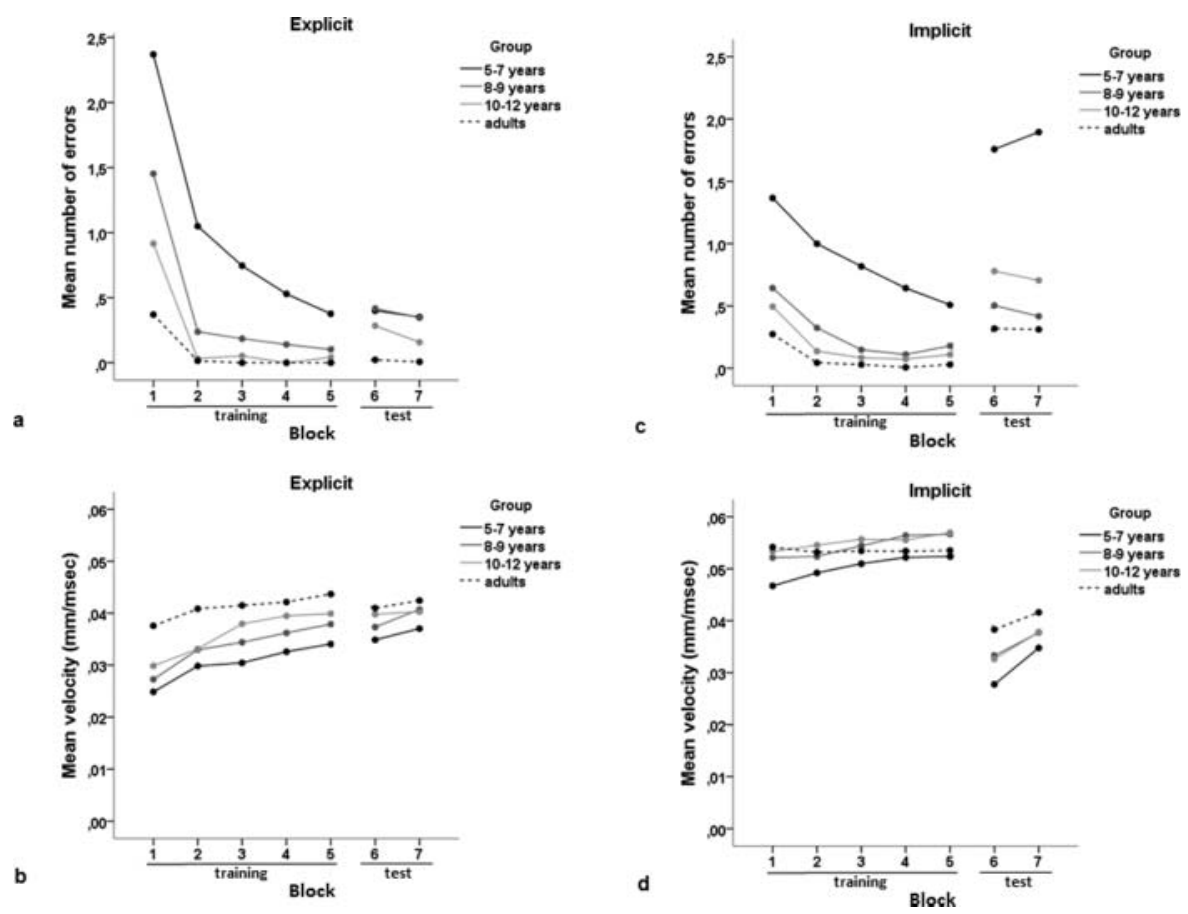

FIGURE 2. Learning of the writing task in the two conditions. The effects of age are shown. (a) Mean number of errors per block for the explicit condition, (b) mean number of errors per block for the implicit condition, (c) mean velocity per block for the explicit condition, (d) mean velocity per block for the implicit condition. 
differences between the explicit and implicit learning method several adaptations to the task were made: (1) for better comparison, both tasks were adapted to more visual tasks (verbal instructions were reduced to a minimum); (2) no feedback was provided during learning in the implicit condition; (3) the learning phase was lengthened; and (4) the test phase was administered after a short break, toncapture learning better.

For the present study, the task was adapted and reprogrammed in Psychopy 2. The writing task is a computerized task, in which handwriting is measured by using a graphics tablet (Wacom XY-tablet, Intuos 3). Nine white landmarks (11 $\mathrm{mm}$ in diameter) were always visible on the computer screen, and acted as landmarks for the movement pattern. Two different trajectories (abstract patterns) each consisting of 7-elements, comparable to the cursive capital ' $\mathrm{H}$ ', with a total length of approximately $39 \mathrm{~cm}$ were used (see Figure 1). In order to reproduce the stimulus patterns the cursor had to pass the nine landmarks in one of five possible ways, i.e., at the inside (between the landmark and the center landmark), at the outside, by encircling it clockwise or anticlockwise, or by stopping in the landmark.

The start and end positions of the sequence were marked by a green and a red dot. Participants' own pen position was shown as a little blue dot. Onsets and offsets were determined by using the PsychoPy isPressedIn method of the circular stimulus (visual Circle). If the participants held their pen in the green dot for $300 \mathrm{~ms}$ (wait time, determined by counting the number of frames in which the pointer was positioned in the green dot), a high beep sounded indicating the start of the trial (start time was measured from the start of the beep, so after wait time). When the participants reached the red dot, a low beep sounded to indicate the end of the trial (stop time was the moment of the first frame refresh after the pointer was positioned in the red dot).

All participants performed both the explicit and implicit condition of the learning task and the two different letterlike patterns in a counterbalanced design, leading to four different test sequences (see Table 1). Each participant was assigned to one of these sequences. Two different patterns were used during the explicit and implicit condition, which had the same trajectory length and consisted of the same elements (see Figure 1). Both parts of the learning task consisted of 25 training trials (divided in 5 blocks of 5 trials), a short break, and a 10 trial test phase (divided in 2 blocks of 5 trials) in each condition. In the explicit condition, participants were told to learn a sequence pattern and participants received extrinsic feedback. The nine landmarks were presented to the participant and the sequence pattern was shown in gray (see Figure 1). When participants held their pen at the start position, a high beep sounded indicating the start of the trial. Subsequently, the pattern disappeared and participants were asked to reproduce the pattern as well as possible by moving the blue pen dot. Their pen trace was shown on screen. When participants reached the end position, the pattern reappeared below their own pen trace until the start of the next trial, to give visual feedback.

In the implicit condition, only the landmarks were presented to the participants throughout the implicit training phase, participants were not informed about the pattern and participants learned by moving along an invisible prerecorded trajectory. Participants were instructed to follow a yellow-colored dot (5 mm diameter) on the computer screen by moving a non-inking pen on the graphics tablet. The yellow dot appeared when participants had started the trial. This dot moved with a natural speed along the invisible pre-recorded trajectory and the participant was asked to follow the dot as closely as possible with the blue dot of their pen (their pen trace was not shown on screen). The invisible pre-recorded trajectory was recorded with the timing characteristics of a well-trained teacher and these timing characteristics incorporated natural changes and stops in velocity at the proper positions (see also Overvelde \& Hulstijn, 2011b).

After the 25 training trials of either condition, there was a short break in which a game was played with the test administrator. After the break, a test phase of another 10 trials (divided in 2 blocks of 5 trials) was assessed. In this test phase, we tested which teaching method was more effective, and lead to better reproduction. Participants had to reproduce the learned sequences without the help of the moving target or the visible pattern. The start and end position were still marked, and while performing the task their pen trace was shown on screen. This sequence of trainingbreak-test phase was similar for the explicit and implicit condition.

\section{Working Memory}

The Automated Working Memory Assessment (AWMA) is a computer-based assessment of short-term and working memory skills in individuals aged 4-22 years (Alloway, 2007). The screening test consists of two tests: listening recall to assess verbal working memory and spatial recall to assess visual working memory. The raw scores of each subtest were separately converted into standardized scores ( $M=100, \mathrm{SD}=15)$. The test-retest reliability of these subtests is .88 and .79 , respectively, for children and adolescents between 4.10 years to 22.5 years (Alloway, 2007).

\section{Motor Proficiency}

The Movement Assessment Battery for Children - Second Edition (MABC-2; Henderson, Sugden, \& Barnett, 2007; Dutch version: Smits-Engelsman, 2010) was used to assess manual dexterity in children with three different subtests. For ages 3-6 (age band 1) the MABC-2 NL contains the subtests Posting Coins, Threading Beads, and Drawing Trail 1, for ages 7-10 (age band 2) it contains the subtests Placing Pegs, Threading Lace, and Drawing Trail 2, for ages 11-16 (age band 3) it contains the subtests 
Turning Pegs, Constructing a Triangle, and Drawing Trail 3. Raw scores are converted into a standard score $(M=10$, $\mathrm{SD}=3$ ) for the subtests and total manual dexterity score. The MABC-2 NL is valid and reliable (Henderson et al., 2007; Smits-Engelsman, 2010).

For adult students, fine manual dexterity was assessed with the Purdue Pegboard Test (Tiffin \& Asher, 1948). Participants had to place as many pins as possible from top to bottom in a wooden board with small holes within $30 \mathrm{~s}$ with their dominant hand. The number of pins placed is the outcome score. The Purdue Pegboard Test is sufficiently reliable (Buddenberg \& Davis, 2000). The Purdue Pegboard Test scores were transformed in a $Z$-score for analyses.

\section{Data Analysis}

The Wacom Intuos 3 tablet samples at $200 \mathrm{~Hz}$. The recorded $x y$-data were oversampled at $500 \mathrm{~Hz}$ for children of 5-9 years, and at $1000 \mathrm{~Hz}$ for older participants. For all participants, data were analyzed at $500 \mathrm{~Hz}$ in Matlab (Matlab R2012a, Mathworks). During training and test phase, accuracy was operationalized as the number of errors, and movement duration and distance were registered to calculate a velocity score. The number of errors per trial was determined by counting the number of landmarks that were incorrectly passed, with a maximum of seven errors per trial, corresponding to the seven landmarks within each trajectory (excluding the start and end position). Next, we calculated movement duration and distance. Movement duration (in msec) was determined by measuring the required time to perform the letter-like pattern from the start position to the end position. Distance of the trajectory (in $\mathrm{mm}$ ) was determined by measuring the distance between the $\mathrm{X}$ and $\mathrm{Y}$ points for all samples in the trial between the start and end, and adding these distances. Movement duration and distance were combined into an average velocity score $(\mathrm{mm} / \mathrm{msec})$. Some trials $(<1 \%)$ were removed from the data, since participants did not start writing the pattern in these trials or lifted the pen from the digitizer during the trial. In SPSS, the removed trials were imputed using Multiple Imputation.

SPSS version 22.0 was used for all statistical analyses. Descriptive statistics of participant characteristics and outcomes on visual working memory and motor proficiency were analyzed for children and adults separately. Next, we divided the group of children in three different age bands: 5-7 years, 8-9 years, and 10-12 years. For each condition, we conducted repeated measures ANOVA for the training blocks ( 5 blocks by 4 age groups $(5-7,8-9,10-12$ years, adults) for both the number of errors and velocity, with a post hoc test (LSD) for the age groups. To test the effects of verbal and visual working memory, repeated measures ANOVAs were repeated with these covariates. For adults and children separately, we also checked whether motor proficiency was a significant factor. All analyses were repeated for the test phase of 2 blocks ( 2 blocks by 2 conditions (explicit, implicit)). When sphericity could not be assumed, results of the Greenhouse-Geisser were reported. Statistical significance $(\alpha)$ was set at $p<0.05$.

\section{Results}

Five of the participating children had incomplete measures due to technical deficiencies and data of these children was excluded. In total, data of 76 children $(37$ males; 5-7 year olds: $n=28,8-9$ year old: $n=29,10-12$ year old: $n=19$ ) and 27 adults (14 males) was further processed. Gender was equally divided across age groups, and hand dominance was similar to what was previously reported in a typical population (Perelle \& Ehrman, 1994). Motor proficiency of children was within the typical range, adults scored slightly lower than the norm score of Mathiowetz, Rogers, Dowe-Keval, Donahoe and Rennels (1986). Working memory scores were higher than norm scores (Alloway, 2007). Descriptive statistics of participating children and adults and results of one sample $t$-tests are shown in Table 2. Below, results of the analysis for explicit learning are given first, followed by results of implicit learning. Finally the comparison of explicit and implicit learning is presented. In Figure 2 the number of errors accross blocks of the learning task and velocity throughout the learning task are depicted for the different age groups. In Table 3, means are presented for the number of errors and velocity per condition. The effect of motor proficiency was not significant in any of the analyses and is therefore not further discussed. Furthermore, we did not find order effects of the four different test sequences.

\section{Explicit Condition}

\section{Number of Errors}

The number of errors decreased during training, $F$ (1.77, $174.96)=135.50, p<.001, \eta^{2}=.58$. Age groups performed significantly different, $F(3,99)=19.36, p<.001$, $\eta^{2}=.37$, with the youngest children making significantly more errors than the other age groups $(p<.001)$, and 8 - to 9 -year-olds making more errors than adults $(p<.01)$. The learning curve was significantly different, that is steeper, for the youngest children, as reflected by the interaction between block and age group, $F(5.30,174.96)=12.52, p$ $<.001, \eta^{2}=.28$. When working memory was added to the analysis, the effect of block was no longer significant. The effect of age group remained, $F(3,97)=14.53, p<.001$, $\eta^{2}=.31$, as did the interaction between block and age group, $F(5.30,171.31)=9.78, p<.001, \eta^{2}=.23$. Scores on the visual and verbal working memory tests were not significant factors.

During test, there were no effects of block or age group on the number of errors. Working memory was also not a significant factor. 
TABLE 2. Group characteristics and outcome measures tests.

\begin{tabular}{|c|c|c|c|c|c|}
\hline & $\begin{array}{c}\text { Children } \\
\text { Total group }\end{array}$ & $5-7$ years & $8-9$ years & $10-12$ years & Adults \\
\hline $\mathrm{N}$ & 76 & 28 & 29 & 19 & 27 \\
\hline Gender (Male/Female) & $37 / 39$ & $16 / 12$ & $12 / 17$ & $9 / 10$ & $14 / 13$ \\
\hline Age in years, $M(\mathrm{SD})$ & $8.6(1.9)$ & $6.6(0.9)$ & $9.0(0.5)$ & $11.1(0.7)$ & $19.8(1.3)$ \\
\hline Dominant hand (Left/Right) & $5 / 71$ & $2 / 26$ & $2 / 27$ & $1 / 18$ & $1 / 26$ \\
\hline \multicolumn{6}{|l|}{ Manual dexterity } \\
\hline $\begin{array}{l}\text { MABC-2 Manual Dexterity, } \\
\text { M (SD) }\end{array}$ & $10.4(3.0)$ & $9.9(2.8)$ & $11.2(3.2)$ & $9.9(3.0)$ & - \\
\hline Purdue Pegboard score, $M$ (SD) & - & - & - & - & $14.6(1.6)$ \\
\hline \multicolumn{6}{|l|}{ AWMA } \\
\hline verbal working memory score, $M(\mathrm{SD})$ & $112.1(14.1)$ & $116.5(14.5)$ & $110.1(12.4)$ & $108.5(15.2)$ & $113.8(14.8)$ \\
\hline visual working memory score, $M$ (SD) & $112.8(13.7)$ & $107.4(15.2)$ & $114.7(11.6)$ & $118.0(11.9)$ & $118.5(14.2)$ \\
\hline
\end{tabular}

\section{Velocity}

Velocity increased during training, $F(3.02,299.08)$ $=48.53, p<.001, \eta^{2}=.33$. Age groups performed significantly different, $F(3,99)=9.42, p<.001, \eta^{2}=.22$. The youngest children were significantly slower than 10 - to 12 year-olds $(p<.05)$. All children were significantly slower than adults $(5-7$ years and $8-9$ years, $p<.001 ; 10$ 12 years, $p<.05$ ). No further interactions were found. When working memory was added to the analysis, the effect of block was no longer present. The effect of age group remained significant, $F(3,97)=7.62, p<.001, \eta^{2}=.19$. There was no effect of verbal or visual working memory.
Velocity increased during test, $F(1.00,99.00)=13.48$, $p<.001, \eta^{2}=.12$. There was no effect of age group, nor was there any interaction. When working memory was added in the analysis, the effect of block was no longer present. There were also no effects of age group or working memory.

\section{Implicit Condition}

\section{Number of Errors}

The number of errors decreased during training, $F$ (2.75, $272.06)=34.47, p<.001, \eta^{2}=.26$. Age groups performed

TABLE 3. Learning task - Means and Standard Deviations of the outcome measures per group.

\begin{tabular}{|c|c|c|c|c|c|c|c|c|}
\hline \multirow[b]{3}{*}{ Number of Errors $M(\mathrm{SD})$} & \multicolumn{6}{|c|}{ Children } & \multicolumn{2}{|c|}{ Adults } \\
\hline & \multicolumn{2}{|c|}{$5-7$ years } & \multicolumn{2}{|c|}{$8-9$ years } & \multicolumn{2}{|c|}{$10-12$ years } & \multirow[b]{2}{*}{ Explicit } & \multirow[b]{2}{*}{ Implicit } \\
\hline & Explicit & Implicit & Explicit & Implicit & Explicit & Implicit & & \\
\hline Training Block 1 & $2.37(1.47)$ & $1.37(0.78)$ & $1.45(0.72)$ & $0.64(0.61)$ & $0.92(0.60)$ & $0.49(0.58)$ & $0.37(0.53)$ & $0.27(0.39)$ \\
\hline Training Block 2 & $1.05(1.14)$ & $1.00(0.89)$ & $0.24(0.33)$ & $0.32(0.46)$ & $0.03(0.14)$ & $0.14(0.33)$ & $0.01(0.05)$ & $0.04(0.13)$ \\
\hline Training Block 3 & $0.75(0.92)$ & $0.82(0.73)$ & $0.19(0.37)$ & $0.15(0.28)$ & $0.05(0.19)$ & $0.08(0.18)$ & $0.00(0.00)$ & $0.03(0.07)$ \\
\hline Training Block 4 & $0.53(0.79)$ & $0.64(0.67)$ & $0.14(0.30)$ & $0.11(0.21)$ & $0.00(0.00)$ & $0.07(0.12)$ & $0.00(0.00)$ & $0.01(0.04)$ \\
\hline Training Block 5 & $0.38(0.60)$ & $0.51(0.58)$ & $0.10(0.27)$ & $0.18(0.34)$ & $0.04(0.18)$ & $0.11(0.15)$ & $0.00(0.00)$ & $0.03(0.09)$ \\
\hline Test Block 6 & $0.40(0.66)$ & $1.76(1.49)$ & $0.42(1.43)$ & $0.50(0.82)$ & $0.28(1.05)$ & $0.78(1.21)$ & $0.02(0.08)$ & $0.32(0.68)$ \\
\hline Test Block 7 & $0.35(0.62)$ & $1.89(1.69)$ & $0.35(1.31)$ & $0.42(0.85)$ & $0.16(0.69)$ & $0.71(1.25)$ & $0.01(0.04)$ & $0.31(0.66)$ \\
\hline \multicolumn{9}{|c|}{ Velocity (mm/msec; M(SD)) } \\
\hline Training Block 1 & $0.02(0.01)$ & $0.05(0.01)$ & $0.03(0.01)$ & $0.05(0.01)$ & $0.03(0.01)$ & $0.05(0.01)$ & $0.04(0.01)$ & $0.05(0.00)$ \\
\hline Training Block 2 & $0.03(0.01)$ & $0.05(0.01)$ & $0.03(0.01)$ & $0.05(0.01)$ & $0.03(0.01)$ & $0.05(0.01)$ & $0.04(0.01)$ & $0.05(0.00)$ \\
\hline Training Block 3 & $0.03(0.01)$ & $0.05(0.01)$ & $0.03(0.01)$ & $0.05(0.01)$ & $0.04(0.01)$ & $0.06(0.01)$ & $0.04(0.01)$ & $0.05(0.00)$ \\
\hline Training Block 4 & $0.03(0.01)$ & $0.05(0.01)$ & $0.04(0.01)$ & $0.06(0.01)$ & $0.04(0.01)$ & $0.06(0.01)$ & $0.04(0.01)$ & $0.05(0.00)$ \\
\hline Training Block 5 & $0.03(0.01)$ & $0.05(0.01)$ & $0.04(0.01)$ & $0.06(0.01)$ & $0.04(0.01)$ & $0.06(0.00)$ & $0.04(0.01)$ & $0.05(0.00)$ \\
\hline Test Block 6 & $0.03(0.01)$ & $0.03(0.01)$ & $0.04(0.01)$ & $0.03(0.01)$ & $0.04(0.01)$ & $0.03(0.01)$ & $0.04(0.01)$ & $0.04(0.01)$ \\
\hline Test Block 7 & $0.04(0.01)$ & $0.03(0.01)$ & $0.04(0.01)$ & $0.04(0.01)$ & $0.04(0.01)$ & $0.04(0.01)$ & $0.04(0.01)$ & $0.04(0.01)$ \\
\hline
\end{tabular}


significantly different, $F(3,99)=26.648, p<.001$, $\eta^{2}=.45$. The youngest children made significantly more errors than the other groups $(p<.001)$, and 8 - to 9 - yearolds made more errors than adults $(p<.05)$. The learning curve was significantly different, that is steeper for the youngest children, as reflected by the interaction between block and age group, $F(2.75,272.06)=2.76, p<.001$, $\eta^{2}=.08$. When working memory was added in the analysis, the effect of block was no longer significant. The effect of age group remained, $F(3,97)=19.29, p<.001, \eta^{2}=$ .37 , as did the interaction between block and age group, $F$ $(8.29,268.10)=2.13, p<.05, \eta^{2}=.06$. Scores on the visual and verbal working memory tests were not significant factors.

The number of errors was not different between the two test blocks. The youngest children performed significantly poorer than the other age groups, $F(3,99)=10.65$, $p<.001, \eta^{2}=.24$, post-hoc test $p<.001$ for all three comparisons. When working memory was added in the analysis, the effect of age group remained, $F(3,97)=8.52, p<.001$, $\eta^{2}=.21$. Scores on visual and verbal working memory tests were not significant factors.

\section{Velocity}

Velocity increased during training, $F(2.92,289.28)$ $=6.92, p<.001, \eta^{2}=.07$. Age groups performed significantly different, $F(3,99)=3.79, p<.05, \eta^{2}=.10$. The youngest children were significantly slower than 8- to 9 -year-olds and 10 - to 12 -year-olds $(p<.01)$, and adults $(p<.05)$. There was no interaction between block and age group. When working memory was added in the analysis, the effects of block and age group were no longer significant. There was also no effect of verbal or visual working memory.

Velocity increased during test, $F(1.00,99.00)=95.06, p<$ $.001, \eta^{2}=.49$. Age groups performed significantly different, $F(3,99)=7.26, p<.001, \eta^{2}=.18$. The youngest children were significantly slower than 8 - to 9 -year-olds $(p<.05)$ and adults $(p<.001)$. Eight- to nine-year-olds and 10- to 12-yearolds were also significantly slower than adults $(p<.05)$. There was no interaction between block and age group. When working memory was added in the analysis, the effect of block was no longer significant. The effect of age group remained, $F$ $(3,97)=6.03, p<.01, \eta^{2}=.16$. There was no effect of verbal or visual working memory.

\section{Explicit vs. Implicit Condition}

\section{Number of Errors}

For the number of errors made during training, there was no difference for condition, participants performed similar in the implicit and explicit condition. During training, the number of errors decreased, $F(2.28,225.58)=157.27$, $p<.001, \eta^{2}=.61$. There was an effect of age group,
$F(3,99)=32.71, p<.001, \eta^{2}=.50$. Post-hoc analysis revealed that 5 - to 7 -year-olds made significantly more errors than the other age groups $(p<.001)$, and 8 - to 9 -year-olds also made more errors than adults $(p<.01)$. There were significant interactions between condition $x$ block $\left(F(2.00,197.57)=27.78, p<.001, \eta^{2}=.22\right)$, block $\times$ age group $\left(F(6.84,225.58)=13.28, p<.001, \eta^{2}=.29\right)$, and condition $\times$ block $\times$ age group $(F(5.99,197.57)=3.50$, $p<.01, \eta^{2}=.10$ ). Adults reached a floor effect (minimum error score) already at block 2 , whereas children were still making errors.

For the number errors made during test, there was an effect for condition, $F(1.00,99.00)=17.67, p<.001$, $\eta^{2}=.15$. More errors were made in the implicit condition. There was also an effect of age group, $F(3,99)=8.73$, $p<.001, \eta^{2}=.21$. Five- to seven-year-olds made significantly more errors than the other groups (for 8- to 9-yearolds and adults $p<.001$, for 10 - to 12 -year-olds $p<.01$ ) There was a significant interaction between condition $\times$ age group, $F(3.00,99.00)=5.23, p<.01, \eta^{2}=.14$. Fiveto seven-year-old children made more errors in the implicit condition than in the explicit condition.

\section{Velocity}

Velocity was higher in the implicit condition, $F$ (1.00, $9.00)=381.27, p<.001, \eta^{2}=.79$. Velocity increased during training, $F(2.81,277.74)=45.08, p<.001, \eta^{2}=.31$. There was an effect of age group, $F(3,99)=9.97, p<$ $.001, \eta^{2}=.23$. Post-hoc analysis revealed that 5 - to 7-yearolds had lower velocity than 8 - to 9-year-olds $(p<.01), 10$ to 12 -year-olds and adults $(p<.001)$. Eight- to nine-yearolds also performed slower than adults $(p<.05)$. There were significant interactions of condition $\times$ block $(F(3.19$, $\left.315.77)=9.14, p<.001, \eta^{2}=.08\right)$, condition $\times$ age group $\left(F(3.00,99.00)=4.62, p<.01, \eta^{2}=.12\right.$, and block $\mathrm{x}$ age group $\left(F(8.42,277.74)=2.09, p<.05, \eta^{2}=.06\right)$. In the implicit condition, differences in velocity between blocks and age groups were smaller than in the explicit condition.

Velocity during test was lower in the implicit condition, $F$ $(1.00,99.00)=14.45, p<.001, \eta^{2}=.13$. Velocity increased during the test phase, $F(1.00,99.00)=76.00, p<.001$, $\eta^{2}=.43$. There was an effect of age group, $F(3,99)=6.62, p<.001, \eta^{2}=.17$. Post-hoc analysis revealed that 5 - to 7 -year-olds had lower velocity than 8 - to 9 -year-olds and 10- to 12 -year-olds $(p<.05)$, and adults $(p<.001)$. Eight- to nine-year-olds also performed slower than adults $(p<.05)$. There was a significant interaction of condition $\times$ block $(F(1.00,99.00)=22.92, p<.001$, $\eta^{2}=.19$ ). The difference in velocity between test blocks was larger in the implicit condition than in the explicit condition.

\section{Discussion}

In this study, we examined explicit and implicit learning of writing new letter-like patterns in a population of 
typically developing children and adults and which teaching method lead to better reproduction in the test phase. We expected explicit learning to be more effective in learning the letter-like patterns. During training, accuracy was not different between conditions, but accuracy was better in the explicit test condition following training. During training, velocity was higher in the implicit condition, but during the test phase, velocity was lower in the implicit condition than in the explicit condition. These results confirm the hypothesis that explicit learning is more effective for typically developing children and adults both in terms of accuracy and velocity. Second, we expected positive effects of both age and working memory on explicit learning but not on implicit learning. The results showed that age indeed positively affected motor learning. At the same time, our results indicate that age affects both explicit as well as implicit learning. Younger children, in particular the youngest group of children, performed with lower accuracy and velocity than the other groups. In the test phase following the implicit condition, these differences between age groups remained. Contrary to our expectations, working memory did not affect the explicit nor implicit learning of letter-like patterns. These findings will be discussed below.

Our finding that explicit learning may be more effective in learning to write letter-like patterns is in line with studies on handwriting instructions and therapeutic interventions (Berninger et al., 1997; Naka, 1998; Smits-Engelsman et al., 2013; Vinter \& Chartrel, 2010), and with previous experimental studies (Jongbloed-Pereboom et al., 2015; Overvelde \& Hulstijn, 2011b). Although during training, participants had a higher velocity in the implicit condition and performed similar on accuracy, participants performed better in the test phase after the explicit condition: accuracy and velocity were higher than after the implicit condition. Berninger et al. (1997)) found that the combination of giving visual cues before writing, loading memory and then reproducing a letter pattern was most effective in teaching handwriting. This was also the case in our explicit condition: participants observed the pattern with its marked startand end point. Following the start of writing, the pattern disappeared and participants reproduced it from memory. When the end point is reached, visual feedback was provided. In the implicit condition, participants did not follow these steps, but were given visual cues only (landmarks and the moving dot). Visual feedback was not provided, but participants learn the movement by doing. Naka (1998) showed that learning to write without a pen trace is more difficult. In the implicit condition, it was not until the test phase that participants were asked to reproduce the pattern from memory and were able to see their written pattern. This may explain the differences in results between training and test phase in the implicit condition. We chose for this set-up, because if we would not have shown the pen trace, the task would have been too difficult to perform for the (youngest) children. Second, this set-up related most to the school situation: if children learn handwriting implicitly by tracing letters, eventually children will be asked to write the letters with their pen on paper.

Age had an effect on both explicit and implicit learning. This was in contrast with our expectation, where we expected a positive effect of age on explicit, but not on implicit learning. Our results showed that children clearly improved writing in the explicit condition. However, age also positively affected implicit learning. It can be speculated that participants also employed more explicit strategies during implicit training or the implicit test phase, e.g., to anticipate the trajectory of the moving target, this may explain why age had an effect on the implicit condition. In line with this reasoning, it has been argued that implicit and explicit processes may not have to be strictly distinct, and participants may become explicitly aware during implicit learning, in which case explicit processes can contribute to learning (Thomas \& Nelson, 2001, Vinck et al., 2012; Willingham, 1998). Our hypotheses regarding the effects of age were based on studies with a serial reaction time task. This task may be regarded to be more of a sequence learning task, than learning a new motor skill. The pattern writing task that we used is also a sequence learning task, but an important difference with previous sequence learning tasks (e.g., Destrebecqz \& Cleeremans, 2001; Nissen \& Bullemer, 1987) is that our task involves more complex perceptual motor skills that include processes such as visual-motor coordination, movement programming, cognitive and perceptual skills, kinesthetic, and tactile processing (Berninger et al., 1992; Feder \& Majnemer, 2007). Based on this reasoning it is likely to assume that individual factors such as age affect learning differently across different tasks, and that age is but only one factor of the many factors important for learning to write.

Verbal- and visual working memory test scores did not affect explicit nor implicit learning. This is in line with our expectation regarding implicit learning. Still, based on the combined motor learning theories (Fitts \& Possner, 1967; Halsband \& Lange, 2006; Maxwell et al., 2003), the theory of handwriting (Berninger et al., 1997), and an experimental study by Kellog, Olive, and Piolat (2007) we did expect to find an effect of working memory on explicit learning. The latter study indeed showed involvement of working memory during written language production (Kellog et al., 2007). Conversely, in our recent study (JongbloedPereboom et al., 2015), using a previous version of the present task, we also failed to find an effect of visual working memory on explicit learning. Two plausible explanations may account for these findings. First, it is possible that working memory should be tested differently, that is, more directly during or towards the end of the learning process (e.g. with a dual task), instead of tested as a separate measure. Second, writing abstract patterns is distinct from writing language. In the latter, motor and orthographic information is integrated, a process that is different from visual perception (Berninger et al., 1992; Jones \& Christensen, 1999). However, to distinguish between implicit and 
explicit learning of handwriting patterns across this broad age range, it was necessary to use abstract patterns. In this way, we were also able to ensure that the different patterns were similar in both difficulty and length.

Scores on both verbal and visual working memory were high in both adults and children. Yet, they were normally distributed. A higher score than the mean standard score of 100 was expected for our adult subjects, as they were all university students. For children, the higher scores on memory are in line with our previous studies (JongbloedPereboom et al., 2015; Jongbloed-Pereboom, Nijhuis-van der Sanden, \& Steenbergen, submitted). These combined results indicate that the UK norm scores are not appropriate for young Dutch children. For the present study, data were ranked and the exact score was not important for the analyses. However, before using this test in diagnostic studies, Dutch norms for young children should be established.

Motor proficiency was tested for all subjects. Children had typical motor proficiency, i.e. their scores were similar to a norm population (Henderson et al., 2007; Smits-Engelsman, 2010). For the adult motor proficiency score, we observed the opposite as the Purdue Pegboard scores were lower than expected from norm scores (Mathiowetz et al., 1986). Norm scores for the Purdue pegboard date from 30 years ago. In a recent study, we observed a similar diminished motor performance over this time range for gross manual dexterity (e.g., Jongbloed-Pereboom, Nijhuis-van der Sanden, \& Steenbergen, 2013), apparently manual dexterity scores have deteriorated over the last decades. We found that motor proficiency did neither affect explicit nor implicit learning to write patterns. In contrast, in our previous study with children with physical and multiple disabilities and controls, we did find an effect of motor proficiency on learning to write (Jongbloed-Pereboom et al., 2015). Other studies found positive correlations between manual dexterity and handwriting tests (Hartingsveldt et al., 2015; Hartingsveldt, Cup, Groot, \& Nijhuis-van der Sanden, 2014). In fact, poor handwriters can be distinguished based on their manual dexterity score of the movement assessment battery for children Smits-Engelsman et al., 2001; Volman, Van Schendel, \& Jongmans, 2006). In addition, fine motor measures were predictive for handwriting speed (Hartingsveldt et al., 2015). In all these studies, children were selected based on their writing skills. Good and poor writers were distinguished from average writers and only the good and poor writers were subsequently tested on quality of handwriting and handwriting speed. In our study, we did not classify children based on their writing skills, and the average manual dexterity score was as expected comparable to the norm score and with a normal standard deviation. This may have caused our lack of an effect of motor proficiency on learning to write.

Strengths of this study were the counterbalanced design and the relatively large group of typically developing children that participated. The results showed that several aspects warrant further investigation. First, the learning processes in the implicit and explicit condition should be further examined. In the present study, we chose to minimize extrinsic feedback in the implicit condition to not disturb the counterbalanced design and because we wanted to enlarge the contrast between conditions. In future studies, it would be useful to test implicit and/or explicit awareness of the learned pattern after training in the implicit condition, in order to establish if participants indeed learned implicitly, and to vary the amount of feedback given in the implicit condition. The use of either implicit or explicit learning paradigms, cannot ascertain that implicit or explicit learning actually occurs or not. Although the use of explicit instructions and extrinsic feedback during practice (i.e., an explicit practice context) typically aims for building up declarative knowledge, we did not directly test this. Similarly, the use of an implicit learning paradigm does not always lead to implicit learning, i.e., participants not being able to report the sequence verbally. While these facets of explicit and implicit motor learning are increasingly acknowledged in the literature, the methods by which the actual learning process can be determined (e.g., number of reported rules) are yet to be tested on validity and reliability. Regarding feedback, experts in the field of explicit and implicit motor learning did not reach consensus on the necessity of giving feedback in implicit learning conditions, although most experts pleat for at least given (limited) feedback about the results (Kleynen et al., 2015).

Other aspects that may be further investigated are the effect of working memory on learning, retention of learning, and applicability of these results to other populations of children. It would be useful to also include a more direct measure of working memory in future studies, for example using a double task. This may provide more insight in the role of working memory in learning handwriting. It would also be interesting to add a long term retention test, to test if explicit learning remains more effective than implicit learning in the longer term. Finally, motor skill learning should be further tested in populations of atypically developing children. Children with physical and multiple disabilities and children with Down Syndrome seem to have a preference for implicit learning of handwriting (JongbloedPereboom et al., 2015; Vinter \& Detable, 2008) and children with intellectual disabilities increase their physical activity after implicit training of overhand throwing (Capio, Poolton, Sit, Eguia, \& Masters, 2013). For learning to write, but also for learning other motor skills, studies should be undertaken to give insight in the best teaching method for atypically developing children.

To conclude, this study showed that for typically developing children and adults it may be more effective to learn letter-like writing patterns in an explicit manner. Age had positive effects on both explicit and implicit learning, whereas working memory did not affect learning to write. Although more research is necessary on the learning processes underlying the explicit and implicit conditions, 
based on the results we recommend a more explicit teaching method for learning to write letter patterns in mainstream primary education. Future studies should focus on teaching methods in atypically developing children and what the exact role is of working memory in handwriting.

\section{ACKNOWLEDGMENTS}

This study was funded by the Faculty of Social Sciences of the Radboud University. We would like to thank all participating children, their parents and teachers, and all participating students. We would like to thank Wouter Hulstijn for his help in instructing his version of the writing task, and the Technical Support Group (in particular Wilbert van Ham) for their help in making the adaptations to the present version of the task. Finally, we thank Anouk van der Heide for her help in collecting the data.

\section{ORCID}

M. W. G. Nijhuis-van der Sanden (D) http://orcid.org/ 0000-0003-2637-6877

\section{REFERENCES}

Abbott, R. D., \& Berninger, V. W. (1993). Structural Equation Modeling of Relationships among Developmental Skills and Writing Skills in Primary-Grade and Intermediate-Grade Writers. Journal of Educational Psychology, 85(3), 478-508. doi:10.1037/0022-0663.85.3.478.

Alloway, T. P. (2007). Automated working memory assessment Dutch translation. London: PEarson Assessment and Information B.V. Translated and reproduced with permission of Pearson Assessment and Information B.V.

APA (2013). Diagnostic and Statistical Manual of Mental Disorders (5th rev. ed.).Washington, DC: American Psychiatric Association.

Berninger, V. W., Vaughan, K. B., Abbott, R. D., Abbott, S. P., Woodruff Rogan, L., Brooks, A., Reed, E., \& Graham, S. (1997). Treatment of handwriting problems in beginning writers: Transfer from handwriting to composition. Journal of Educational Psychology, 89, 652-666. doi:10.1037/00220663.89.4.652.

Berninger, V., Yates, C., Cartwright, A., Rutberg, J., Remy, E., \& Abbott, R. (1992). Lower-level developmental skills in beginning writing. Reading and Writing, 4(3), 257-280. doi:10.1007/ BF01027151.

Blank, R., Smits-Engelsman, B., Polatajko, H., \& Wilson, P. (2012). European Academy for Childhood Disability (EACD): Recommendations on the definition, diagnosis and intervention of developmental coordination disorder. Developmental Medicine and Child Neurology, 54, 54-93. doi:10.1111/j.14698749.2011.04171.x.

Bosga-Stork, I., Overvelde, A., Van Bommel-Rutgers, I., Van Cauteren, M., Halfwerk, B., Nijhuis-van der Sanden, R., \& Smits-Engelsman, B. (2009). [Inventory of referral patterns, research and treatment of children with writing problems. A digital survey]. Nederlands Tijdschrift voor Kinderfysiotherapie, 21, 14-18. [In Dutch].

Buddenberg, C. A., \& Davis, C. (2000). Test-retest reliability of the Purdue Pegboard Test. American Journal of Occupational Therapy, 54, 555-5588. doi:10.5014/ajot.54.5.555.
Capio, C. M., Poolton, J. M., Sit, C. H. P., Eguia, K. F., \& Masters, R. S. W. (2013). Reduction of errors during practice facilitates fundamental movement skills in children with intellectual disabilities. Journal of Intellectual Disability Research, 57(4), 295-305. doi:10.1111/j.1365-2788.2012.01535.x.

Clements, S. D. (1966). Minimal brain dysfunction in children: Terminology and identification. Washington, DC: US Department of Health Education and Welfare.

Destrebecqz, A., \& Cleeremans, A. (2001). Can sequence learning be implicit? New evidence with the process dissociation procedure. Psychonomic Bulletin and Review, 8, 343-350. doi:10.3758/BF03196171.

Dinehart, L. H. (2014). Handwriting in early childhood education: Current research and future implications. Journal of Early Childhood Literacy, 15(1), 97-118. doi:10.1177/ 1468798414522825.

Drempt, N. van, McCluskey, A., \& Lannin, N. A. (2011). A review of factors that influence adult handwriting performance. Australian Journal of Occupational Therapy, 58, 321-328. doi:10.1111/j.1440-1630.2011.00960.x.

Feder, K. P., \& Majnemer, A. (2007). Handwriting development, competency, and intervention. Review. Developmental Medicine \& Child Neurology, 49, 312-317. doi:10.1111/j.14698749.2007.00312.x.

Fitts, P. M., \& Posner, M. I. (1967). Human performance. Belmont, California: BRooks/Cole publishing company.

Graham, S., Harris, K., Mason, L., Fink-Chorzempa, B., Moran, S., \& Saddler, B. (2008). How do primary grade teachers teach handwriting? A national survey. Reading and Writing, 21, 4969. doi:10.1007/s11145-007-9064-z.

Halsband, U., \& Lange, R. K. (2006). Motor learning in man: A review of functional and clinical studies. Journal of Physiology, 99, 414-424.

Hammerschmidt, S., \& Sudsawad, P. (2004). Teachers' survey on problems with handwriting: Referral, evaluation, and outcomes. American Journal of Occupational Therapy, 58(2), 185-192. doi:10.5014/ajot.58.2.185.

Hamstra-Bletz, L., \& Blöte, A. (1993). A longitudinal study on dysgraphic handwriting in primary school. Journal of Learning Disabilities, 26, 689-699. doi:10.1177/002221949302601007.

Hartingsveldt, M. J., van, Cup, E. H. C., Groot, I. de, \& Nijhuis-van der Sanden, M. W. G. (2014). Writing Readiness Inventory Tool in Context (WRITIC): Reliability and convergent validity. Australian Occupational Therapy Journal, 61, 102-109. doi: 10.1111/1440-1630.12082 doi:10.1111/1440-1630.12082.

Hartingsveldt, M. J., van, Cup, E. H. C., Hendriks, J. C.M., Vries, L. de, Groot, I. de, \& Nijhuis-van der Sanden, M. W. G. (2015). Predictive validity of kindergarten assessments on handwriting readiness. Research in Developmental Disabilities, 36, 114124. doi:10.1016/j.ridd.2014.08.014.

Henderson, S. E., Sugden, D. A., \& Barnett, A. L. (2007). Movement Assessment Battery for Children-2, Second Edition (Movement ABC-2). Examiner's Manual. London: HArcourt Assessment.

Jones, D., \& Christensen, C. A. (1999). Relationship between automaticity in handwriting and students' ability to generate written text. Journal of Educational Psychology, 91(1), 44-49. doi:10.1037/0022-0663.91.1.44.

Jongbloed-Pereboom, M., Nijhuis-van der Sanden, M. W.G., \& Steenbergen, B. Explicit and Implicit Motor Sequence Learning in Children and Adults; the Role of Age and Visual Working Memory. Submitted.

Jongbloed-Pereboom, M., Nijhuis-van der Sanden, M. W. G., \& Steenbergen, B. (2013). Norm scores of the Box and Block Test for children ages 3-10 years. American Journal of Occupational Therapy, 67(3), 312-318. doi:10.5014/ajot.2013.006643. 
Jongbloed-Pereboom, M., Peeters, A., Overvelde, A., Nijhuis-van der Sanden, M. W. G., \& Steenbergen, B. (2015). Learning of writing letter-like sequences in children with physical and multiple disabilities. Research in Developmental Disabilities, 36, 150-161. doi:10.1016/j.ridd.2014.10.005.

Jongmans, M. J., Smits-Engelsman, B. C.M., \& Schoemaker, M. (2003). Consequences of comorbidity of developmental coordination disorders and learning disabilities for severity and pattern of perceptual-motor dysfunction. Journal of Learning Disabilities, 36(6), 528-537. doi:10.1177/ 00222194030360060401.

Karlsdottir, R., \& Stefansson, T. (2002). Problems in developing functional handwriting. Perceptual and Motor Skills, 94, 623662. doi:10.2466/pms.2002.94.2.623.

Kellog, R. T., Olive, T., \& Piolat, A. (2007). Verbal, visual, and spatial working memory in written language production. Acta Psychologica, 124(3), 382-397. doi:10.1016/j.actpsy.2006.02.005.

Kirby, A., Edwards, L., \& Sugden, D. (2011). Emerging adulthood in developmental coordination disorder: Parent and young adult perspectives. Research in Developmental Disabilities, 32, 1351-1360. doi:10.1016/j.ridd.2011.01.041.

Kleynen, M., Braun, S. M., Bleijlevens, M. H., Lexis, M. A., Rasquin, S. M., Halfens, J., Wilson, M. R., Beurskens, A. J., \& Masters, R. S. W. (2014). Using a Delphi technique to seek consensus regarding definitions, descriptions and classification of terms related to implicit and explicit forms of motor learning. Plos One, 9(6), e100227. doi:10.1371/journal.pone. 0100227.

Kleynen, M., Braun, S. M., Rasquin, S. M., Bleijlevens, M. H., Lexis, M. A., Halfens, J., Wilson, M. R., Masters, R. S. W., \& Beurskens, A. J. (2015). Multidisciplinary views on applying explicit and implicit motor learning in practice: An international survey. Plos One, 10(8), e0135522. doi:10.1371/journal.pone.0135522.

Marr, D., Cermak, S., Cohn, E. S., \& Henderson, A. (2003). Fine motor activities in Head Start and kindergarten classrooms. American Journal of Occupational Therapy, 57, 550â€"557. doi:10.5014/ajot.57.5.550.

Mathiowetz, V., \& Rogers, Dowe-Keval (1986). Donahoe, \& Rennels The Purdue Pegboard: Norms for 14- to 19-year-olds. American Journal of Occupational Therapy, 40(3), 174-179. doi:10.5014/ajot.40.3.174.

Maxwell, J. P., Masters, R. S. W., \& Eves, F. F. (2003). The role of working memory in motor learning and performance. Consciousness and Cognition, 12, 376-402. doi:10.1016/S10538100(03)00005-9.

McHale, K., \& Cermak, S. A. (1992). Fine motor activities in elementary school: Preliminary findings and provisional implications for children with fine motor problems. American Journal of Occupational Therapy, 46, 898-903. doi:10.5014/ajot.46.10.898.

Meulemans, T., van der Linden, M., \& Perruchet, P. (1998). Implicit sequence learning in children. Journal of Experimental Child Psychology, 69, 199-221. doi:10.1006/jecp.1998.2442.

Nissen, M. J., \& Bullemer, P. T. (1987). Attentional requirements for learning: Evidence from performance measures. Cognitive Psychology, 19, 1-32. doi:10.1016/0010-0285(87)90002-8.

Naka, M. (1998). Repeated writing facilitates children's memory or pseudocharacters and foreign letters. Memory and Cognition, 26(4), 804-809. doi:10.3758/BF03211399.

Overvelde, A., \& Hulstijn, W. (2011a). Handwriting development in grade 2 and grade 3 primary school children with normal, at risk, or dysgraphic characteristics. Research in Developmental Disabilities, 32(2), 540-548. doi:10.1016/j. ridd.2010.12.027.

Overvelde, A., \& Hulstijn, W. (2011b). Learning new movement patterns: A study on good and poor writing comparing learning conditions emphasizing spatial, timing and abstract characteristics. Human Movement Science, 30, 731-744. doi:10.1016/j. humov.2010.08.016.

Perelle, I. B., \& Ehrman, L. (1994). An International study of human handedness: The data. Behavior Genetics, 24(3), 217227. doi:10.1007/BF01067189.

Poolton, J. M., \& Zachry, T. L. (2007). So you want to learn implicitly? Coaching and learning through implicit learning techniques. International Journal of Sport Science and Coaching, 2(1), 67-78. doi:10.1260/174795407780367177.

Reber, A. S. (1992). The cognitive unconscious: An evolutionary perspective. Consciousness and Cognition, 1, 93-133. doi:10.1016/1053-8100(92)90051-B.

Rourke, B. P., Ahmad, S. A., Collins, D. W., Hayman-Abello, B. A., \& Warriner, E. M. (2002). Child clinical/pediatric neuropsychology: Some recent advances. Annual Review of Psychology, 53, 309-339. doi:10.1146/annurev.psych.53.100901.135204.

Rubin, N., \& Henderson, S. E. (1982). Two sides of the same coin: Variation in teaching methods and failure to learn to write. Special Education, 9, 17-24. doi:10.1111/j.14678578.1982.tb00576.x.

Schmidt, R. A., \& Lee, T. D. (2013). Motor learning and performance: From principles to application. (5th revised edition). Champaign, Illinois:HUman Kinetic Publishers.

Smits-Engelsman, B. C. M. (2010). Nederlandse bewerking van de Movement Assessment Battery for children -2. Handleiding: Pearson. Amsterdam.

Smits-Engelsman, B. C. M., Blank, R., Van der Kaay, A.-C., Mosterd-Van der Meijs, R., Vlugt-Van der Brand, E., \& Polatajko, H. J. et al. (2013). Efficacy of interventions to improve motor performance in children with developmental coordination disorder: A combined systematic review and meta-analysis. Developmental Medicine \& Child Neurology, 55(3), 229-237. doi:10.1111/dmcn.12008.

Smits-Engelsman, B. C. M., Niemeijer, A. S., \& van Galen, G. P. (2001). Fine motor deficiencies in children diagnosed as DCD on poor grapho-motor ability. Human Movement Science, 20 (1-2), 161-182. doi:10.1016/S0167-9457(01)00033-1.

Steenbergen, B., van der Kamp, J., Verneau, M., JongbloedPereboom, M., \& Masters, R. S. W. (2010). Implicit and explicit learning: Application form basic research to sports for individuals with impaired movement dynamics. Disability and Rehabilitation, 32(18), 1509-1516. doi:10.3109/ 09638288.2010.497035.

Tamopol, L., \& Tamopol, M. (1977). Brain function and reading disabilities. Baltimore:UNiversity Park Press.

Thomas, K. M., \& Nelson, C. A. (2001). Serial reaction time learning in preschool- and school-age children. Journal of Experimental Child Psychology, 79, 364-387. doi:10.1006/ jecp.2000.2613.

Tiffin, J., \& Asher, E. J. (1948). The Purdue Pegboard; norms and studies of reliability and validity. J Appl Psychol, 32(3):234247. doi:10.1037/h0061266.

Vinck, A., Maassen, B. A. M., Hulstijn, W., Diender, M. G., Mullaart, R. A., Rotteveel, J. J., \& Nijhuis-van der Sanden, M. W. G. (2012). Motor sequence learning in children with spina bifida. Developmental Neuropsychology, 37(7), 601-616. doi:10.1080/87565641.2012.697502.

Vinter, A., \& Detable, C. (2008). Implicit and explicit motor learning in children with and without Down's syndrome. British Journal of Developmental Psychology, 26(4), 507-523. doi:10.1348/026151007X267300.

Vinter, A., \& Chartrel, E. (2010). Effects of different types of learning on handwriting movements in young children. Learning and Instruction, 20, 476-486. doi:10.1016/j. learninstruc.2009.07.001. 
Volman, M. J. M., Van Schendel, B. M., \& Jongmans, M. J. (2006). Handwriting difficulties in primary school children: A search for underlying mechanisms. American Journal of Occupational Therapy, 60(4), 451-460. doi:10.5014/ajot.60.4.451.

Wechsler, D., \& Naglieri, J. A. (2008). Wechsler non-verbal-NL. Amsterdam:PEarson Assessment and Information B.V.

Willingham, D. B. (1998). A neuropsychological theory of motor skill learning. Psychological Review, 105, 558-584. doi:10.1037/0033-295X.105.3.558.
Wulf, G., Hoss, M., \& Prinz, W. (1998). Instructions for motor learning: Differential effects of internal versus external focus of attention. Journal of Motor Behavior, 30, 169-179. doi:10.1080/00222899809601334.

Received October 10, 2016

Revised October 13, 2017

Accepted November 6, 2017 